\title{
Translesion Synthesis in Plants: Ultraviolet Resistance and Beyond
}

\author{
Ayako N. Sakamoto * \\ Department of Radiation-Applied Biology Research, National Institutes for Quantum and Radiological Science \\ and Technology, Takasaki, Japan
}

Plant genomes sustain various forms of DNA damage that stall replication forks. Translesion synthesis (TLS) is one of the pathways to overcome stalled replication in which specific polymerases (TLS polymerase) perform bypass synthesis across DNA damage. This article gives a brief overview of plant TLS polymerases. In Arabidopsis, DNA polymerase (Pol) $\zeta, \eta, \kappa, \theta$, and $\lambda$ and Reversionless1 (Rev1) are shown to be involved in the TLS. For example, AtPoln bypasses ultraviolet (UV)-induced cyclobutane pyrimidine dimers in vitro. Disruption of AtPol $\zeta$ or AtPoln increases root stem cell death after UV irradiation. These results suggest that AtPol $\zeta$ and ATPoln bypass UV-induced damage, prevent replication arrest, and allow damaged cells to survive and grow. In general, TLS polymerases have low fidelity and often induce mutations. Accordingly, disruption

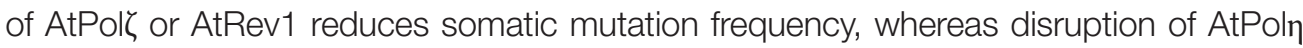
elevates it, suggesting that plants have both mutagenic and less mutagenic TLS activities.

OPEN ACCESS

Edited by:

Alma Balestrazzi,

University of Pavia, Italy

Reviewed by: Wei Xiao,

University of Saskatchewan, Canada Carlos F. M. Menck, University of São Paulo, Brazil

*Correspondence:

Ayako N. Sakamoto sakamoto.ayako@qst.go.jp

Specialty section: This article was submitted to Plant Cell Biology, a section of the journal Frontiers in Plant Science

Received: 20 February 2019 Accepted: 03 September 2019 Published: 09 October 2019

Citation:

Sakamoto AN (2019) Translesion Synthesis in Plants: Ultraviolet Resistance and Beyond.

Front. Plant Sci. 10:1208. doi: 10.3389/fp/s.2019.01208
The stalled replication fork can be resolved by a strand switch pathway involving a DNA helicase Rad5. Disruption of both AtPol and AtRAD5a shows synergistic or additive

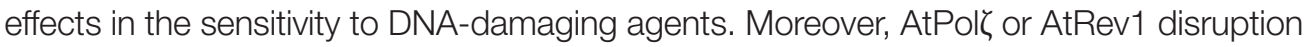
elevates homologous recombination frequencies in somatic tissues. These results suggest that the Rad5-dependent pathway and TLS are parallel. Plants grown in the presence of heat shock protein 90 (HSP90) inhibitor showed lower mutation frequencies, suggesting that HSP90 regulates mutagenic TLS in plants. Hypersensitivities of TLS-deficient plants to $\gamma$-ray and/or crosslink damage suggest that plant TLS polymerases have multiple roles, as reported in other organisms.

Keywords: translesion synthesis, UV, mutation, DNA damage, genome stability

\section{INTRODUCTION}

Accurate replication of genomic DNA is vital for maintaining genome integrity. However, genomic DNA sustains various forms of damage caused by internal and external agents. Ultraviolet (UV) light is a major cause of DNA damage for land plants. It induces the formation of covalent bonds between the two adjacent pyrimidines. The two major products of UV damage, cyclobutane pyrimidine dimers (CPDs) and pyrimidine (6-4) pyrimidone photoproducts [(6-4)PPs], are quickly repaired by the action of CPD and 6-4 photolyases in plant cells (Britt, 1999; Li et al., 2010; Hitomi et al., 2012). In addition, nucleotide excision repair (NER) plays an important role in removing UV damage (Kimura et al., 2004; Kunz et al., 2005; Canturk et al., 2016). Nevertheless, the remaining damage is toxic for cells because it distorts the template structure and prevents replication. This stalled replication creates a fragile single-strand region that easily leads to double-strand breaks 
(DSBs), so organisms have multiple pathways to solve the stalled replication fork. Translesion synthesis (TLS) is one such pathway in which specific polymerases (TLS polymerase) are recruited to the replication machinery and perform the bypass synthesis across the DNA damage (Vaisman and Woodgate, 2017). Figure 1A illustrates the concept of TLS activity. When encountering DNA damage, the replicative polymerase (replicase) stalls because of distorted helix geometry. TLS polymerase, carrying a flexible active site, replaces the replicase and inserts one or more nucleotide(s) opposite the damage. Because of the relaxed constraints of these active sites, the TLS polymerase has a low fidelity and often incorporates one or more incorrect nucleotide(s) that can be removed by the exonuclease activity of replicases or the mismatch repair mechanism. However, unremoved errors result in base substitutions, frameshifts, or other types of mutation. This mutagenic nature of TLS has been linked to the senescence, carcinogenesis, and evolution of organisms.

It is more than a decade since the first report of TLS in plants. The accumulation of reports from multiple groups has clarified the roles and importance of TLS not only in UV resistance but also in the maintenance of genome stability in plants. This minireview aims to summarize 1) TLS activity in plants in comparison with that in other organisms, 2) the contribution of TLS activity to plant responses to DNA-damaging stresses, and 3) possible other functions of TLS polymerases, which may unveil novel damage-resistant mechanisms in plants.

\section{DNA POLYMERASE FAMILY MEMBERS IN PLANTS}

DNA polymerases are classified into seven families based on their amino acid sequence similarity (Ishino and Ishino, 2014). Eukaryotes have Family A, B, X, and Y polymerases, whereas Family $\mathrm{C}$ polymerases are only seen in bacteria and Family D and $\mathrm{E}$ polymerases only in archaea. Arabidopsis has at least 11 polymerases classified into five families based on comparisons with human and yeast homologs (Table 1). The representative member of Family A polymerases is Escherichia coli polymerase I, which was the first DNA polymerase to be identified (Kornberg et al., 1956). Eukaryotic members of this group are polymerase $\gamma(\mathrm{Pol} \gamma)$ and DNA polymerase $\theta(\operatorname{Pol} \theta)$. Arabidopsis also has homologs of two prokaryotic-type DNA polymerases, PolI-like A and B (Parent et al., 2011), as well as AtPol $\theta$, which was originally isolated as the causative gene of the short-root mutant tebichi (Inagaki et al., 2006). Family B polymerases include E. coli Pol II and eukaryotic polymerases $\alpha$ (Pola), $\delta$ (Pol $\delta$ ), and $\varepsilon$ (Pole), which are involved in the replication of nuclear DNA. Pola, $\delta$, and $\varepsilon$ are conserved in Arabidopsis (Ronceret et al., 2005; Shultz et al., 2007; Liu et al., 2010; Iglesias et al., 2015; Pedroza-Garcia et al., 2016). This family includes DNA polymerase $\zeta$, the first identified TLS polymerase that is also conserved in Arabidopsis (Sakamoto et al., 2003). Family X is only conserved in eukaryotes: its representative polymerase is Polymerase $\beta$, which is involved in base excision repair. Humans have four members in Family X (Pol $\beta$, Pol $\lambda$, Pol $\mu$, and terminal deoxytransferase), whereas plants only have Pol $\lambda$, which is phylogenetically distant from the Pol $\lambda$ of other organisms (Filée et al., 2002; Pavlov et al., 2006).
Family Y carries the largest number of TLS polymerases, including

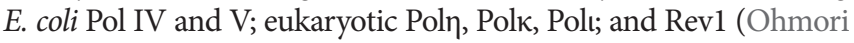
et al., 2001). Rev1 was originally isolated as a responsible gene for yeast reversionless 1 mutant, which carries a deoxycytidyl transferase

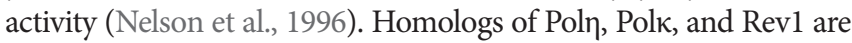
found in Arabidopsis (Takahashi et al., 2007).

Most recently, it has been shown that some members of the Archea-Eucaryotic Primase superfamily, such as human PrimPol, perform bypass synthesis across DNA damage (Iyer et al., 2005; Bianchi et al., 2013; Guilliam et al., 2015). Arabidopsis has a herpes-pox type primase (Iyer et al., 2005), although its function has not yet been investigated.

\section{ISOLATION OF TRANSLESION SYNTHESIS POLYMERASES BASED ON ULTRAVIOLET RESISTANCE}

A UVB-sensitive mutant rev3 was isolated in Arabidopsis by screening ion-beam mutagenized seedlings under nonphotoreactivating conditions (Sakamoto et al., 2003). The responsible gene, AtREV3, encodes a homolog of the catalytic subunit of DNA polymerase $\zeta(\mathrm{Pol} \zeta)$. DNA replication in the rev3 root meristem was reduced after UVB irradiation (Sakamoto et al., 2003). AtREV7 and AtREV1 encode a regulatory subunit of Pol $\zeta$ and a Family Y polymerase, respectively (Takahashi et al., 2005). The rev7 and rev1 plants showed reduced growth compared with wild-type plants under chronic UVB irradiation (Takahashi et al., 2005). AtPOLH encodes a homolog of DNA polymerase $\eta$ (Poln) that complements the yeast rad30 mutant (Santiago et al., 2006). Disruption of Pol $\zeta$ and Poln had an additive effect on Arabidopsis root growth after UVB treatment (Anderson et al., 2008). Moreover, cell death was induced at root stem cells, and the number of mitotic cells was reduced severely in the UV-irradiated

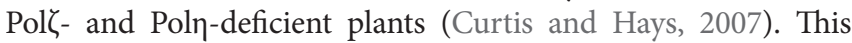
series of studies showed that these polymerases are important in plant UV resistance. The polymerases allow DNA replication to continue, saving the stem cell from cell death and maintaining growth in the presence of harmful UV irradiation.

\section{DAMAGE BYPASS ACTIVITIES OF TRANSLESION SYNTHESIS POLYMERASES}

TLS activity has been investigated in vitro using purified or recombinant polymerases and synthetic damage-inducing templates, such as cyclobutane TT dimer (CTD) and (6-4)TT photoproducts $[(6-4) \mathrm{TP}]$. These analyses revealed that the bypass efficiency is dependent on both the type of damage and the polymerases involved (Figure 1B). For example, yeast and human Poln bypasses CTD efficiently (Johnson et al., 1999; Masutani et al., 1999), but Poln only inefficiently bypasses (6-4)TP (Johnson et al., 2001). In humans, DNA polymerase $ı$ (Polı) inserts a nucleotide opposite $3^{\prime}$-T in the (6-4)TP (Vaisman et al., 2003). The $3^{\prime}$-end is

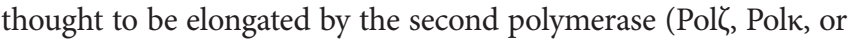


A
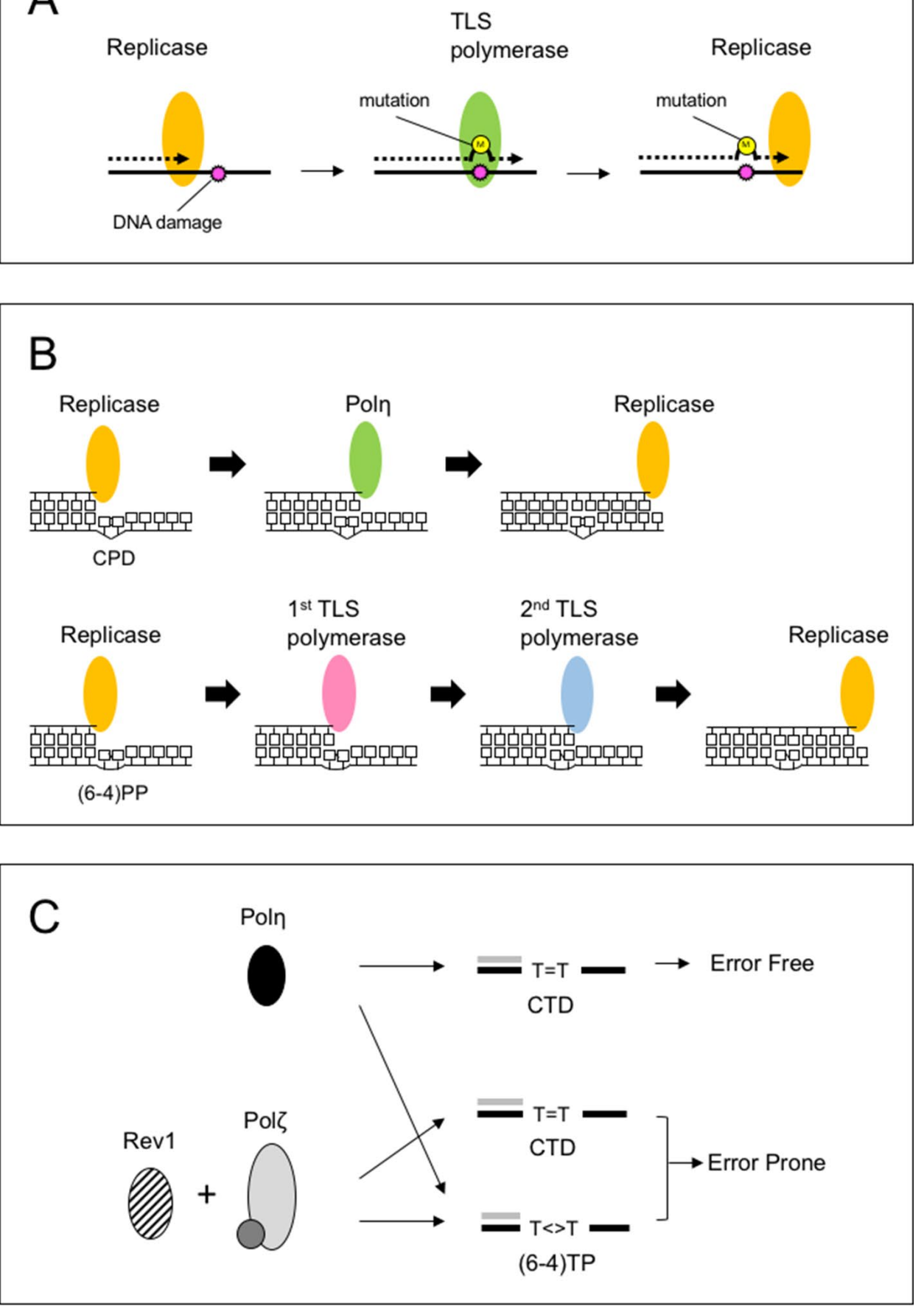

FIGURE 1 | Continued

$\operatorname{Pol} \theta$ ), which has 3 '-end elongation activity (Prakash et al., 2005, Seki and Wood, 2008). The subsequent in vivo analyses suggest that the UV damage at CC or CT sequence are also bypassed by a similar one- or two-step mechanism. Thus, TLS involves the multiple switching of polymerases at the replication site (Figure 1B; Prakash and Prakash, 2002; Bebenek and Kunkel, 2004).
The bypass activity of AtPoln for the major UV damage was examined by two groups who showed that AtPoln bypasses the CTD in vitro (Anderson et al., 2008; Hoffman et al., 2008). The activity of AtPoln is comparable to that of human Poln when examined at optimum salt concentration and temperature, and HsPoln, ScPoln, and AtPoln do not bypass (6-4)TP (Hoffman et al., 2008). 


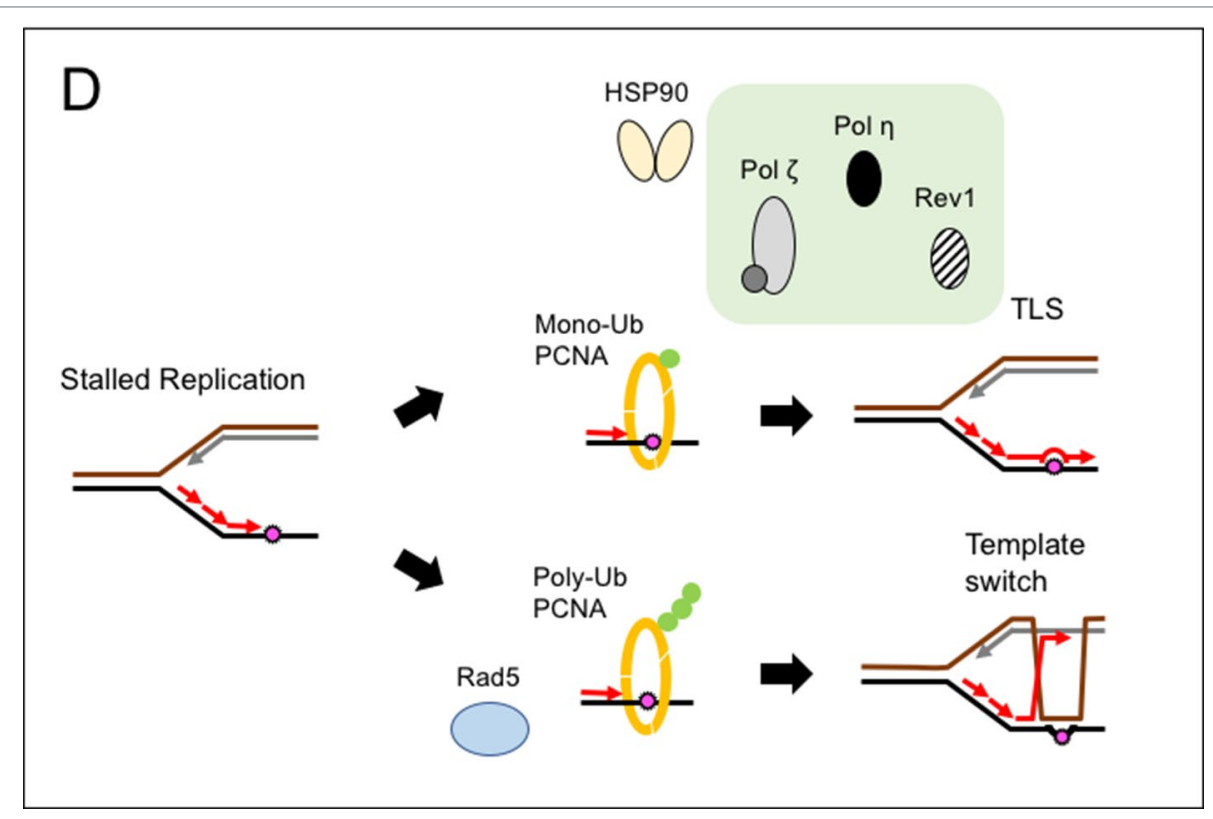

FIGURE 1 | Schematic of translesion synthesis (TLS). (A) Concept of TLS. When encountering DNA damage, the replicase stalls before the damage. TLS polymerase replaces the replicase and inserts one or more nucleotides opposite the damage. Because of the low fidelity, TLS polymerase incorporates one or more incorrect nucleotides, resulting in base substitutions, frameshifts, or other types of mutation. (B) Proposed model for the bypass of two major forms of ultraviolet (UV) damage. The model was proposed from the biochemical activities of TLS polymerases. The cyclobutane pyrimidine dimer (CPD) is efficiently bypassed by Poln (upper). However, no polymerase can complete the bypass of (6-4) photoproducts [(6-4)PP] by itself. Thus, (6-4)PPs may be bypassed by two polymerases, incorporating nucleotides one after the other (lower). (C) A model for UV-induced mutagenesis at the $\Pi T$ site in plants. The cyclobutane $\Pi$ dimer (CTD) is efficiently bypassed by Poln in an error-free manner; any misincorporation

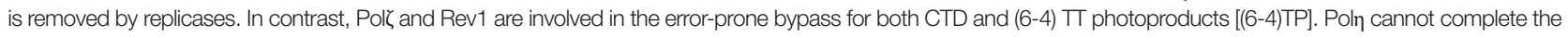
bypass of (6-4)TP, so error-prone bypass is achieved by Polל. (D) A model for damage tolerance mechanism in plants. The stalled replication fork is processed by either of two pathways: mutagenic synthesis by specific TLS polymerases or accurate synthesis using an intact template (template switch). The stalled replication fork signals the modification of PCNA. When PCNA is monoubiquitinated, the TLS polymerases interact with the Ub-PCNA and are recruited to the replication fork. The stalled replication fork also signals the transfer of Poln and Rev1. The 90-kDa heat shock protein (HSP90) promotes TLS activity through interaction with TLS polymerases. When TLS is deficient or reduced by depletion of HSP90, Rad5-dependent polyubiquitination of PCNA leads to a template switch, which causes genome instability.

Research has also been done on other types of DNA damage: AtPolk inserted an A/C opposite 8-oxoG, a common form of oxidative damage induced by reactive oxygen species (GarcíaOrtiz et al., 2007). Deletion of the C-terminal domain elevates the processivity and fidelity of AtPolk, suggesting that the C-terminal domain regulates the activities of this polymerase through interactions with other proteins (García-Ortiz et al., 2004; GarcíaOrtiz et al., 2007). DNA polymerase $\lambda$ bypassed 8 -oxoG in both error-free ( $\mathrm{dC}$ insertion) and error-prone ( $\mathrm{dA}$ insertion) manners (Amoroso et al., 2011). AtRev1 inserted a C opposite an apurin/ apyrimidine (AP) site (Takahashi et al., 2007), which is formed by spontaneous depurination or occurs as an intermediate in the base excision repair process (Boiteux and Guillet, 2004). AtPolIA and AtPolIB have also been shown to bypass the AP site in vitro (Baruch-Torres and Brieba, 2017).

\section{DETECTION OF MUTATIONS INDUCED BY TRANSLESION SYNTHESIS}

Mutations induced by TLS have been investigated in in vivo assay systems (Lawrence and Christensen, 1978; Lawrence and Christensen, 1979; Roche et al., 1994; Harfe and Jinks-Robertson,
2000; Yu et al., 2001; Bresson and Fuchs, 2002; Kozmin et al., 2003; Gibbs et al., 2005; Szüts et al., 2008; Yoon et al., 2009; Yoon et al., 2010). In yeast, the deletion of Pol $\zeta$ or Rev1 reduces the UV-induced mutation frequency (Lawrence and Christensen, 1978, Lawrence and Christensen, 1979), whereas the deletion of Poln increases the frequency (Yu et al., 2001; Kozmin et al., 2003). These observations are not consistent with the in vitro characteristics of Pol $\zeta$ and Poln because Pol $\eta$ is less accurate than $\mathrm{Pol} \zeta$ when replicating undamaged DNA (McCulloch et al., 2007; Zhong et al., 2006). Comprehensive analysis of in vitro and in vivo data suggested that Poln bypasses CTD with some errors, which are removed by the exonuclease activity of other polymerase(s) (McCulloch and Kunkel, 2008). Prakash et al. (2005) suggest that yeast Poln bypasses CPD at CC or CT sequence in an error-free manner. However, Pol $\eta$ seems to induce $\mathrm{C}$ to $\mathrm{T}$ transition by inserting $\mathrm{dA}$ opposite deaminated $\mathrm{C}$ or $\mathrm{mC}$ in CPD (Ikehata and Ono, 2011). Yeast and mammalian Poln bypass (6-4)TP in an error-prone manner (Bresson and Fuchs, 2002; Yoon et al., 2010). It is suggested that $\mathrm{Pol} \zeta$ contributes to the mutagenic bypass of (6-4)PP by extending the mismatched primer end caused by the action of Poln or other polymerases (Prakash et al., 2005; Hirota et al., 2010). Thus, the mutation frequency depends on the polymerases available, damage type, sequence context, and the assay system, and so on. 
TABLE 1 | DNA polymerases in Arabidopsisa,b.

\begin{tabular}{|c|c|c|c|c|c|}
\hline Family & Category & Subunit & $\begin{array}{l}\text { A. thaliana } \\
\text { Gene ID }\end{array}$ & Reference & Function \\
\hline \multirow[t]{3}{*}{ A } & DNA polymerase IA & POLIA & At3g20540 & Parent et al., 2011 & Replication of organellar DNA, TLS \\
\hline & DNA polymerase IB & POLIB & At1g50840 & & Replication of organellar DNA, TLS \\
\hline & DNA polymerase $\theta$ & POLQ & At4g32700 & Inagaki et al., 2006 & $\begin{array}{l}\text { Repair of crosslink damage } \\
\text { DSB repair } \\
\text { TLS }\end{array}$ \\
\hline \multirow[t]{16}{*}{ B } & DNA polymerase $\alpha$ & POLA1 & At5g67100 & Shultz et al., 2007; Liu et al., & Replication \\
\hline & & POLA2 & At1g67630 & 2010 & \\
\hline & & POLA3 & At1g67320 & & \\
\hline & & POLA4 & At5g41880 & & \\
\hline & DNA polymerase $\delta$ & POLD1 & At5g63960 & Shultz et al., 2007; Iglesias & Replication \\
\hline & & POLD2 & At2g42120 & et al., 2015 & \\
\hline & & POLD3 & At1g78650 & & \\
\hline & & POLD4 & At1g09815 & & \\
\hline & DNA polymerase $\varepsilon$ & POLE1 & At1g08260 & Ronceret et al., 2005; & Replication \\
\hline & & POLE2 & At2g27120 & Pedroza-Garcia et al., 2016 & \\
\hline & & POLE3 & At5g22110 & & \\
\hline & & POLE4 & At1g07980 & & \\
\hline & & & At5g43250 & & \\
\hline & & & At2g27470 & & \\
\hline & DNA polymerase $\zeta$ & REV3 & At1g67500 & Sakamoto et al., 2003; & TLS, Repair of crosslink damage \\
\hline & & REV7 & At1g16590 & Takahashi et al., 2005 & DSB repair \\
\hline \multirow[t]{2}{*}{$\mathbf{x}$} & DNA polymerase $\lambda$ & POLL & At1g10520 & Uchiyama et al., 2004 & Repair synthesis \\
\hline & & & & & TLS \\
\hline \multirow[t]{3}{*}{$\mathbf{Y}$} & DNA polymerase $\eta$ & POLH & At5g44740 & Santiago et al., 2006 & TLS, Repair of crosslink damage \\
\hline & DNA polymerase $\kappa$ & POLK & At1g49980 & García-Ortiz et al., 2004 & TLS \\
\hline & Rev1 & REV1 & At5g44750 & Takahashi et al., 2005 & TLS, Repair of crosslink damage \\
\hline
\end{tabular}

aHomologs for DNA polymerase $\sigma$ are not listed here because opinions are divided whether Polo has a DNA polymerase activity or not. ${ }^{b}$ Organellar DNA primases are not listed here.

In plants, the reversion frequencies in Arabidopsis plants were measured using $\beta$-glucuronidase (GUS)-based markers (Kovalchuk et al., 2000; Nakagawa et al., 2011a; Nakagawa et al., 2011b).

The markers carry a G-T mutation, which corresponds to the 3'-T of TT sequence, a possible target of UV dimer. A misincorporation of $\mathrm{dC}$ opposite $3^{3}$-T leads to detect a reversion (a $T$ to $G$ transversion). When irradiated with $U V B$, the Pol $\zeta$ - and Rev1-deficient plants made fewer reversions in somatic cells compared with wild-type plants. By contrast, the Poln-deficient plant showed higher reversion frequencies than wild-type plants, which were reduced in Pol $\zeta$ and Poln double-deficient plants. From these results, the authors proposed a model in which Arabidopsis has two TLS pathways for responding to UV damage: a more mutagenic pathway involving Pol $\zeta$ and Rev1 and a less mutagenic pathway

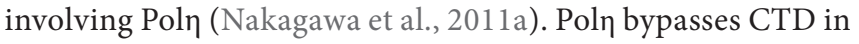
an error-free manner (Figure 1C). Pol $\zeta$ and Rev1 bypass both CTD and (6-4)TP in an error-prone manner. The Poln inserts a nucleotide opposite (6-4)TP, which is extended by $\mathrm{Pol} \zeta$ and causes the mutation. Since the bypass activity across (6-4)TP is low anyway, the minor $\mathrm{dC}$ insertions would be detected in this assay system. However, other explanations are possible, for example, when UV induces a double-strand break near the TT sequence, which is wrongly repaired and causes a mutation. Also, further analysis by employing a C-containing marker is necessary to profile UV-induced mutations in plants.

\section{REGULATION OF TRANSLESION SYNTHESIS}

Maintenance of the replication fork is crucial because stalled replication forks easily lead to strand breaks. It has been suggested that a stalled replication fork signals the modification of proliferating cell nuclear antigen (PCNA), which triggers the switching of replicase to TLS polymerase (Stelter and Ulrich, 2003; Kanao and Masutani, 2017). That is, when the PCNA is monoubiquitinated, the replicase detaches from PCNA and TLS polymerases are recruited to the replication site to perform the bypass of damaged DNA, whereas polyubiquitinated PCNA

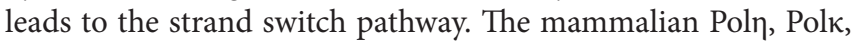
and Rev1 have been shown to interact with monoubiquitinated PCNA through the UBZ or UBM motif located in the C-terminal (Bienko et al., 2005; Wood et al., 2007). Moreover, Rev1 has also been shown to interact with other TLS polymerases (Guo et al., 2003) and is suggested to function as a bridge through which the best polymerase for TLS is selected (Boehm et al., 2016).

Arabidopsis has two copies of PCNA, but only AtPCNA2 complements the yeast pol30 mutant (Anderson et al., 2008). The AtPoln has a UBM motif and two PIP repeats but does not have a UBZ motif conserved in animal and yeast Polns. The mutant AtPoln disrupted in PIP1, PIP2, or UBM still interacts with Arabidopsis PCNA2 but does not fully complement yeast rad30 cells (Anderson et al., 2008). Both Arabidopsis PCNAs interact with ubiquitin in $N$. benthamiana cells and are ubiquitinated in vitro 
(Strzalka et al., 2013). The AtREV1 interacts with PCNA2, AtPoln, and AtREV7, a regulatory subunit of AtPol $\zeta$ in yeast (Sakamoto et al., 2018). The processivity of rice Pol $\lambda$ is stimulated in the presence of PCNA (Uchiyama et al., 2004). Moreover, when Arabidopsis Pol $\lambda$ bypasses 8-oxoG, the ratio of error-free ( $\mathrm{dC}$ insertion) to errorprone ( $\mathrm{dA}$ insertion) bypass changed depending on its interaction with PCNA2 (Amoroso et al., 2011). These results suggest that the modification of PCNA leads to the switching from replicase to the appropriate TLS polymerase in plants.

It has been suggested that stalled replication in plants is also resolved by a Rad5-dependent strand switch pathway (Wang et al., 2011). The rev3 and rad5a mutations caused synergistic or additive effects on root growth in plants exposed to UV, MMS, or crosslink agents compared with plants containing each single mutation (Wang et al., 2011). The rad5a plant failed to induce homologous recombination events after bleomycin treatment (Chen et al., 2008). By contrast, rev3 and rev1 plants induced significantly more recombination events after UV irradiation (Sakamoto et al., 2018). If AtRAD5a and AtREV3 work via two alternative pathways, the elevation of recombination activities in rev3 and rev1 plant could be due to the activation of a RAD5dependent pathway (Figure 1D).

\section{TRANSLESION SYNTHESIS AND HEAT SHOCK PROTEIN 90}

The $90-\mathrm{kDa}$ heat shock protein (HSP90) is an evolutionarily conserved molecular chaperone that stabilizes and activates various proteins involved in homeostasis, transcriptional regulation, chromatin remodeling, and DNA repair (Pennisi et al., 2015). The Arabidopsis genome has four copies of cytosolic HSP90 and three copies of organellar HSP90 (Krishna and Gloor, 2001). Queitsch et al. (2012) reported that the application of geldanamycin, a specific inhibitor of HSP90, to Arabidopsis plants elevated homologous recombination (HR) frequencies, suggesting that the HSP90s are involved in genome maintenance in plants.

Human HSP90 interacts with HsPoln and HsRev1 and regulates the TLS activities (Sekimoto et al., 2010; Pozo et al., 2011). The frequency of UV-induced supF mutation in hPoln-proficient cells is elevated by applying 17-AAG, an HSP90 inhibitor, due to the inhibition of error-free bypass of UV damage (Sekimoto et al., 2010). Conversely, in HsPoln-deficient cells, 17-AAG treatment reduces mutation due to the inhibition of the REV1dependent error-prone bypass (Pozo et al., 2011). In contrast with the results in mammals, treatment with geldanamycin reduces mutation frequencies in wild-type plants, which are AtPoln-proficient (Sakamoto et al., 2018). This suggests that HSP90 mainly regulates the error-prone TLS pathway, involving AtRev1, in Arabidopsis.

\section{TRANSLESION SYNTHESIS AND CELL CYCLE CHECKPOINT}

In Arabidopsis, UVB or gamma irradiation induces programmed cell death of stem and progenitor (StPr) cells in the root meristem that depends on ataxia-telangiectasia mutated (ATM), ataxiatelangiectasia and Rad3-related (ATR), and SUPPRESSOR OF GAMMA RESPONSE1 (Curtis and Hays, 2011; Furukawa et al., 2010). Curtis and Hays (2011) investigated the time course of cell

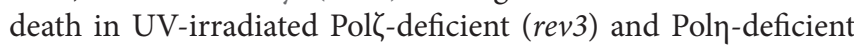
(polh) roots as well as the roots of damage checkpoint kinase atm and atr mutants. They found that the cells in polh plants started dying at around $16 \mathrm{~h}$ after UV treatment, but the cells in rev3 plant started to die at around $20 \mathrm{~h}$. The time courses of cell death in atr and rev3 atr plants were similar to that in rev3 plants, whereas the UV dose-dependency plots of atr, rev3 atr, and rev3 fitted similar slopes. Thus, they hypothesized that there are two types of TLS in Arabidopsis StPr cells: rapid TLS involving Poln and

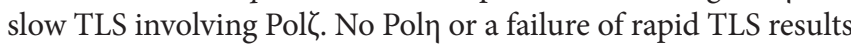
in the accumulation of single-stranded DNA, which activates a damage checkpoint and Pol bypasses the damage (slow TLS). If both Pol $\eta$ and Pol $\zeta$ are absent, or if Pol $\eta$ and ATR are absent, then the stalled replication fork collapses to produce DSB, and the ATM activates DSB repair pathways. A similar epistatic relationship between ATR and Pol $\zeta$ was observed in yeast; the Polל-dependent mutation requires the yeast ATR homolog Mec1 (Pagès et al., 2009). Therefore, some, but not all, of the TLS activities appear to be controlled by checkpoint activation in both plants and microorganisms.

REV7, the regulatory subunit of Pol $\zeta$, contains a HORMA (Hop1, Rev7, and MAD2) domain (Aravind and Koonin, 1998). Based on its homology to MAD2, the key component of the mitotic-spindle-assembly checkpoint, and Hop1, a meioticsynaptonemal complex component, it has been speculated that REV7 acts as an adaptor for DNA repairs and the spindle assembly checkpoint (Aravind and Koonin, 1998). Human REV7 makes a homodimer, and REV7-MAD2 a heterodimer, in vitro (Murakumo et al., 2000). In the absence of REV7, human cells arrest in the G2/M-phase and display increased monoastral and abnormal spindles with misaligned chromosomes (Bhat et al., 2015). Crystal structure and NMR analyses showed that two copies of REV7 bind to the canonical REV7-binding motifs (RBMs) of REV3 (Rizzo et al., 2018). In plants, Arabidopsis REV7 makes a homodimer in both the nucleus and the cytosol (Sakamoto et al., 2018). However, there is only one repeat of RBM in AtREV3 sequences, which is similar to yeast REV3 (Tomida et al., 2015). Therefore, the conformation of active Pol $\zeta$ in plants could be different from that in mammals.

\section{TRANSLESION SYNTHESIS DNA POLYMERASE IN THE REPAIR OF DOUBLE-STRAND BREAKS OR CROSSLINK DAMAGE}

Substantial evidence points to the involvement of TLS polymerases in the DSB repair pathway. For example, chicken REV3(-/-) cells and Arabidopsis rev3 plants are sensitive to ionizing radiation (Sakamoto et al., 2003; Sonoda et al., 2003). Arabidopsis Pol $\lambda$-disruption plants are hypersensitive to ionizing radiation and bleomycin (Furukawa et al., 2016). In yeast, Pol $\zeta$ and Rev1 are associated with the homing endonuclease 
(HO)-induced DSB end (Hirano and Sugimoto, 2006). Moreover, ScREV3 is responsible for mutations near the HO-induced cleavage site (Holbeck and Strathern, 1997; Rattray et al., 2002). These results show that some TLS polymerases, at least, have a role in DSB-repair processes in both animals and plants. Recently, DNA polymerase $\theta$ was shown to be involved in the alternative end-joining (Alt-EJ) pathway in animals (Chan et al., 2010; Wood and Doublié, 2016; Schimmel et al., 2017) and in moss (Mara et al., 2019). PolO-deficient Arabidopsis cannot integrate T-DNA, suggesting that the Pol $\theta$ stabilizes two minimally paired 3 ' overhanging DNA ends during the T-DNA integration process (van Kregten et al., 2016). It is possible that TLS polymerases work in DSB repair pathway in some context.

$\operatorname{Pol} \theta$ is the best understood polymerase involved in the repair of interstrand crosslink (ICL) damage (Harris et al., 1999; Shima et al., 2003; Beagan et al., 2017). Other TLS polymerases have also been suggested to work in the process of ICL damage repair. For example, REV3(-/-) cells or organisms are sensitive to ICLinducing treatments in mammals, chickens, yeast, and plants (Grossmann et al., 2000; Sakamoto et al., 2003; Nojima et al., 2005; Takahashi et al., 2005; Sarkar et al., 2006; Sharma et al., 2012). Disruption of Rev1 and Poln makes the cell or organism hypersensitive to ICL treatment (Takahashi et al., 2005; Sharma et al., 2012), and hPoln can bypass the ICL adduct in vitro (Vaisman et al., 2000). It has been suggested that ICL damage is processed by the Fanconi anemia complementation group A (FANCA)-dependent pathway, which includes nucleolytic incision, TLS, and HR (Kim and D'Andrea, 2012). Several TLS polymerases have been shown to bypass ICL damage if the DNA around the ICL is appropriately trimmed (Ho et al., 2011; Roy et al., 2016). These data suggest that TLS activities are important in overcoming ICL damage. In conclusion, TLS polymerases have multiple roles, which are critical for the genome stability of animals, plants, and microorganisms.

\section{REFERENCES}

Amoroso, A., Concia, L., Maggio, C., Raynaud, C., Bergounioux, C., Crespan, E., et al. (2011). Oxidative DNA damage bypass in Arabidopsis thaliana requires DNA polymerase $\lambda$ and proliferating cell nuclear antigen 2. Plant Cell. 23, 806822. doi: 10.1105/tpc.110.081455

Anderson, H. J., Vonarx, E. J., Pastushok, L., Nakagawa, M., Katafuchi, A., Gruz, P., et al. (2008). Arabidopsis thaliana Y-family DNA polymerase eta catalyses translesion synthesis and interacts functionally with PCNA2. Plant J. 55, 895908. doi: 10.1111/j.1365-313X.2008.03562.x

Aravind, L., and Koonin, E. V. (1998). The HORMA domain: a common structural denominator in mitotic checkpoints, chromosome synapsis and DNA repair. Trends Biochem. Sci. 23, 284-286. doi: 10.1016/S0968-0004(98)01257-2

Baruch-Torres, N., and Brieba, L. G. (2017). Plant organellar DNA polymerases are replicative and translesion DNA synthesis polymerases. Nucleic Acids Res. 45, 10751-10763. doi: 10.1093/nar/gkx744

Beagan, K., Armstrong, R. L., Witsell, A., Roy, U., Renedo, N., Baker, A. E., et al. (2017). Drosophila DNA polymerase theta utilizes both helicase-like and polymerase domains during microhomology-mediated end joining and interstrand crosslink repair. PLoS Genet. 13, e1006813. doi: 10.1371/journal. pgen.1006813

Bebenek, K., and Kunkel, T. A. (2004). Function of DNA polymerases. Adv. Protein Chem. 69, 137-165. doi: 10.1016/S0065-3233(04)69005-X

\section{CONCLUSION AND FUTURE PERSPECTIVES}

The deletion of TLS polymerase often causes lethal or severe phenotypes in animals (Esposito et al., 2000; O-Wang et al., 2002; Wittschieben et al., 2006; Dumstorf et al., 2006; Stallons and McGregor, 2010). By contrast, almost all TLS polymerase activities can be disrupted in plants without severe reduction of fertility. Therefore, the plant system is ideal for analyzing the function, regulation, and interaction of TLS polymerases. Information on the structure and catalytic fidelity of TLS polymerases can assist us to build a novel genome-editing enzyme with elaborate specificities. Plant cells can provide a good platform for developing these upcoming technologies.

\section{AUTHOR CONTRIBUTIONS}

ANS wrote all the parts of this mini-review.

\section{FUNDING}

This work was partially supported by Japan Society for the Promotion of Science (JSPS) KAKENHI Grant number 24241028, 25440147, and $17 \mathrm{~K} 00561$ to AS.

\section{ACKNOWLEDGMENTS}

The author thanks Shinya Takahashi for his critical reading of the manuscript. She also thanks Ann Seward and Sarah Williams, ELS, from Edanz Group (www.edanzediting.com/ac) for editing a draft of this manuscript.

Bhat, A., Wu, Z., Maher, V. M., McCormick, J. J., and Xiao, W. (2015). Rev7/Mad2B plays a critical role in the assembly of a functional mitotic spindle. Cell Cycle 14, 3929-3938. doi: 10.1080/15384101.2015.1120922

Bianchi, J., Rudd, S. G., Jozwiakowski, S. K., Bailey, L. J., Soura, V., Taylor, E., et al. (2013). PrimPol bypasses UV photoproducts during eukaryotic chromosomal DNA replication. Mol. Cell. 52, 566-573. doi: 10.1016/j.molcel.2013.10.035

Bienko, M., Green, C. M., Crosetto, N., Rudolf, F., Zapart, G., Coull, B., et al. (2005). Ubiquitin-binding domains in Y-family polymerases regulate translesion synthesis. Science 310, 1821-1824. doi: 10.1126/science.1120615

Boehm, E. M., Spies, M., and Washington, M. T. (2016). PCNA tool belts and polymerase bridges form during translesion synthesis. Nucleic Acids Res. 44, 8250-8260. doi: 10.1093/nar/gkw563

Boiteux, S., and Guillet, M. (2004). Abasic sites in DNA: repair and biological consequences in Saccharomyces cerevisiae. DNA Repair 3, 1-12. doi: 10.1016/j. dnarep.2003.10.002

Bresson, A., and Fuchs, R. P. (2002). Lesion bypass in yeast cells: Pol Z participates in a multi-DNA polymerase process. EMBO J. 21, 3881-3887. doi: 10.1093/ emboj/cdf363

Britt, A. B. (1999). Molecular genetics of DNA repair in higher plants. Trends Plant. Sci. 4, 20-25. doi: 10.1016/S1360-1385(98)01355-7

Canturk, F., Karaman, M., Selby, C. P., Kemp, M. G., Kulaksiz-Erkmen, G., Hu, J., et al. (2016). Nucleotide excision repair by dual incisions in plants. Proc. Natl. Acad. Sci. U.S.A. 113, 4706-4710. doi: 10.1073/pnas.1604097113 
Chan, S. H., Yu, A. M., and McVey, M. (2010). Dual roles for DNA polymerase theta in alternative end-joining repair of double-strand breaks in Drosophila. PLoS Genet. 6, e1001005. doi: 10.1371/journal.pgen.1001005

Chen, I. P., Mannuss, A., Orel, N., Heitzeberg, F., and Puchta, H. (2008). A homolog of ScRAD5 is involved in DNA repair and homologous recombination in Arabidopsis. Plant Physiol. 146, 1786-1796. doi: 10.1104/pp.108.116806

Curtis, M. J., and Hays, J. B. (2007). Tolerance of dividing cells to replication stress in UVB-irradiated Arabidopsis roots: requirements for DNA translesion polymerases eta and zeta. DNA Repair 6, 1341-1358. doi: 10.1016/j.dnarep. 2007.03.004

Curtis, M. J., and Hays, J. B. (2011). Cooperative responses of DNA-damageactivated protein kinases ATR and ATM and DNA translesion polymerases to replication-blocking DNA damage in a stem-cell niche. DNA Repair 10, 12721281. doi: 10.1016/j.dnarep.2011.10.001

Dumstorf, C. A., Clark, A. B., Lin, Q., Kissling, G. E., Yuan, T., Kucherlapati, R., et al. (2006). Participation of mouse DNA polymerase iota in strand-biased mutagenic bypass of UV photoproducts and suppression of skin cancer. Proc. Natl. Acad. Sci. U.S.A. 103, 18083-18088. doi: 10.1073/pnas.0605247103

Esposito, G., Godindagger, I., Klein, U., Yaspo, M. L., Cumano, A., and Rajewsky, K. (2000). Disruption of the Rev3l-encoded catalytic subunit of polymerase $\zeta$ in mice results in early embryonic lethality. Curr. Biol. 10, 1221-1224. doi: 10.1016/S0960-9822(00)00726-0

Filée, J., Forterre, P., Sen-Lin, T., and Laurent, J. (2002). Evolution of DNA polymerase families: evidences for multiple gene exchange between cellular and viral proteins. J. Mol. Evol. 54, 763-773. doi: 10.1007/s00239-001-0078-X

Furukawa, T., Curtis, M. J., Tominey, C. M., Duong, Y. H., Wilcox, B. W., Aggoune, D., et al. (2010). A shared DNA-damage-response pathway for induction of stem-cell death by UVB and by gamma irradiation. DNA Repair (Amst.) 9, 940-948. doi: 10.1016/j.dnarep.2010.06.006

Furukawa, T., Angelis, K. J., and Britt, A. B. (2016). Arabidopsis DNA polymerase lambda mutant is mildly sensitive to DNA double strand breaks but defective in integration of a transgene. Front. Plant Sci. 6, 357. doi: 10.3389/ fpls.2015.00357

García-Ortiz, M. V., Ariza, R. R., Hoffman, P. D., Hays, J. B., and Roldán-Arjona, T. (2004). Arabidopsis thaliana AtPOLK encodes a DinB-like DNA polymerase that extends mispaired primer termini and is highly expressed in a variety of tissues. Plant J. 39, 84-97. doi: 10.1111/j.1365-313X.2004.02112.x

García-Ortiz, M. V., Roldán-Arjona, T., and Ariza, R. R. (2007). The noncatalytic C-terminus of AtPOLK Y-family DNA polymerase affects synthesis fidelity, mismatch extension and translesion replication. FEBS J. 274, 3340-3350. doi: 10.1111/j.1742-4658.2007.05868.x

Gibbs, P. E. M., McDonald, J., Woodgate, R., and Lawrence, C. W. (2005). The Relative Roles in vivo of Saccharomyces cerevisiae Pol $\eta$, Pol $\zeta$, Rev1 Protein and Pol32 in the Bypass and Mutation Induction of an Abasic Site, T-T (6-4) Photoadduct and T-T cis-syn Cyclobutane Dimer. Genetics 169, 575-582. doi: 10.1534/genetics.104.034611

Grossmann, K. F., Ward, A. M., and Moses, R. E. (2000). Saccharomyces cerevisiae lacking Snm1, Rev3 or Rad51 have a normal S-phase but arrest permanently in G2 after cisplatin treatment. Mutat. Res. 461, 1-13. doi: 10.1016/ S0921-8777(00)00035-5

Guilliam, T. A., Keen, B. A., Brissett, N. C., and Doherty, A. J. (2015). Primasepolymerases are a functionally diverse superfamily of replication and repair enzymes. Nucleic Acids Res. 43, 6651-6664. doi: 10.1093/nar/gkv625

Guo, C., Fischhaber, P. L., Luk-Paszyc, M. J., Masuda, Y., Zhou, J., Kamiya, K., et al. (2003). Mouse rev1 protein interacts with multiple DNA polymerases involved in translesion DNA synthesis. EMBO J. 22, 6621-6630. doi: 10.1093/emboj/ cdg626

Harfe, B. D., and Jinks-Robertson, S. (2000). DNA polymerase zeta introduces multiple mutations when bypassing spontaneous DNA damage in Saccharomyces cerevisiae. Mol. Cell. 6, 1491-1499. doi: 10.1016/S1097-2765(00)00145-3

Harris, P. V., Mazina, O. M., Leonhardt, E. A., Case, R. B., Boyd, J. B., and Burtis, K. C. (1999). Molecular cloning of Drosophila mus308, a gene involved in DNA cross-link repair with homology to prokaryotic DNA polymerase I genes. Mol. Cell. Biol. 16, 5764-5771. doi: 10.1128/MCB.16.10.5764

Hirano, Y., and Sugimoto, K. (2006). ATR homolog Mecl controls association of DNA polymerase zeta-Rev1 complex with regions near a double-strand break. Curr. Biol. 16, 586-590. doi: 10.1016/j.cub.2006.01.063
Hirota, K., Sonoda, E., Kawamoto, T., Motegi, A., Masutani, C., Hanaoka, F., et al. (2010). Simultaneous disruption of two DNA polymerases, Poln and Pol $\zeta$, in avian DT40 cells unmasks the role of Poln in cellular response to various DNA lesions. PLoS Genet. 6, e1001151. doi: 10.1371/journal.pgen.1001151

Hitomi, K., Arvai, A. S., Yamamoto, J., Hitomi, C., Teranishi, M., Hirouchi, T., et al. (2012). Eukaryotic class II cyclobutane pyrimidine dimer photolyase structure reveals basis for improved ultraviolet tolerance in plants. J. Biol. Chem. 287, 12060-12069. doi: 10.1074/jbc.M111.244020

Ho, T. V., Guainazzi, A., Derkunt, S. B., Enoiu, M., and Schärer, O. D. (2011). Structure-dependent bypass of DNA interstrand crosslinks by translesion synthesis polymerases. Nucleic Acids Res. 39, 7455-7464. doi: 10.1093/nar/ gkr448

Hoffman, P. D., Curtis, M. J., Iwai, S., and Hays, J. B. (2008). Biochemical evolution of DNA polymerase eta: properties of plant, human, and yeast proteins. Biochem. 47, 4583-4596. doi: 10.1021/bi701781p

Holbeck, S. L., and Strathern, J. N. (1997). A role for REV3 in mutagenesis during double-strand break repair in Saccharomyces cerevisiae. Genetics 147, 1017-1024.

Iglesias, F. M., Bruera, N. A., Dergan-Dylon, S., Marino-Buslje, C., Lorenzi, H., Mateos, J. L., et al. (2015). The Arabidopsis DNA polymerase $\delta$ has a role in the deposition of transcriptionally active epigenetic marks, development and flowering. PLoS Genet. 11, e1004975. doi: 10.1371/journal.pgen. 1004975

Ikehata, H., and Ono, T. (2011). The mechanisms of UV mutagenesis. J. Radiat. Res. 52, 115-125. doi: 10.1269/jrr.10175

Inagaki, S., Suzuki, T., Ohto, M. A., Urawa, H., Horiuchi, T., Nakamura, K., et al. (2006). Arabidopsis TEBICHI, with helicase and DNA polymerase domains, is required for regulated cell division and differentiation in meristems. Plant Cell. 18, 879-892. doi: 10.1105/tpc. 105.036798

Ishino, S., and Ishino, Y. (2014). DNA polymerases as useful reagents for biotechnology the history of developmental research in the field. Front. Microbiol. 5, 465. doi: 10.3389/fmicb.2014.00465

Iyer, L. M., Koonin, E. V., Leipe, D. D., and Aravind., L. (2005). Origin and evolution of the archaeo-eukaryotic primase superfamily and related palmdomain proteins: structural insights and new members. Nucleic Acids Res. 33, 3875-3896. doi: 10.1093/nar/gki702

Johnson, R. E., Haracska, L., Prakash, S., and Prakash, L. (2001). Role of DNA polymerase eta in the bypass of a (6-4) TT photoproduct. Mol. Cell. Biol. 21, 3558-3563. doi: 10.1128/MCB.21.10.3558-3563.2001

Johnson, R. E., Prakash, S., and Prakash, L. (1999). Efficient bypass of a thyminethymine dimer by yeast DNA polymerase, Pol eta. Science 283, 1001-1004. doi: $10.1126 /$ science.283.5404.1001

Kanao, R., and Masutani, C. (2017). Regulation of DNA damage tolerance in mammalian cells by post-translational modifications of PCNA. Mutat. Res. 803-805, 82-88. doi: 10.1016/j.mrfmmm.2017.06.004

Kim, H., and D'Andrea, D. (2012). Regulation of DNA cross-link repair by the Fanconi anemia/BRCA pathway. Genes Dev. 26, 1393-1408. doi: 10.1101/ gad.195248.112

Kimura, S., Tahira, Y., Ishibashi, T., Mori, Y., Mori, T., Hashimoto, J., et al. (2004). DNA repair in higher plants; photoreactivation is the major DNA repair pathway in non-proliferating cells while excision repair (nucleotide excision repair and base excision repair) is active in proliferating cells. Nucleic Acids Res. 32, 2760-2767. doi: 10.1093/nar/gkh591

Kornberg, A., Lehman, I. R., Bessman, M. J., and Simms, E. S. (1956). Enzymic synthesis of deoxyribonucleic acid. Biochim. Biophysl. Acta 21, 197-198. doi: 10.1016/0006-3002(56)90127-5

Kovalchuk, I., Kovalchuk, O., and Hohn, B. (2000). Genome-wide variation of the somatic mutation frequency in transgenic plants. EMBO J. 19, 4431-4438. doi: 10.1093/emboj/19.17.4431

Kozmin, S. G., Pavlov, Y. I., Kunkel, T. A., and Sage, E. (2003). Roles of Saccharomyces cerevisiae DNA polymerases Poleta and Polzeta in response to irradiation by simulated sunlight. Nucleic Acids Res. 31, 4541-4552. doi: 10.1093/nar/gkg489

Krishna, P., and Gloor, G. (2001). The Hsp90 family of proteins in Arabidopsis thaliana. Cell Stress Chaperones 6, 238-246. doi: 10.1379/1466-1268(2001)006< 0238:THFOPI>2.0.CO;2

Kunz, B. A., Anderson, H. J., Osmond, M. J., and Vonarx, E. J. (2005). Components of nucleotide excision repair and DNA damage tolerance in Arabidopsis thaliana. Environ. Mol. Mutagen. 45, 115-127. doi: 10.1002/em.20094 
Lawrence, C. W., and Christensen, R. B. (1978). Ultraviolet-induced reversion of $c y c 1$ alleles in radiation-sensitive strains of yeast I. rev1 mutant strains. L. Mol. Biol. 122, 1-21. doi: 10.1016/0022-2836(78)90104-3

Lawrence, C. W., and Christensen, R. B. (1979). Ultraviolet-induced reversion of $c y c 1$ alleles in radiation-sensitive strains of yeast III. rev 3 mutant strains. Genetics. 92, 397-408.

Li, J., Liu, Z., Tan, C., Guo, X., Wang, L., Sancar, A., et al. (2010). Dynamics and mechanism of repair of ultraviolet-induced (6-4) photoproduct by photolyase. Nature 466, 887-890. doi: 10.1038/nature09192

Liu, J., Ren, X., Yin, H., Wang, Y., Xia, R., Wang, Y., et al. (2010). Mutation in the catalytic subunit of DNA polymerase alpha influences transcriptional gene silencing and homologous recombination in Arabidopsis. Plant J. 61, 36-45. doi: 10.1111/j.1365-313X.2009.04026.x

Mara, K., Charlot, F., Guyon-Debast, A., Schaefer, D. G., Collonnier, C., Grelon, M., et al. (2019). POLQ plays a key role in the repair of CRISPR/Cas9-induced double-stranded breaks in the moss Physcomitrella patens. New Phytol. 222, 1380-1391. doi: 10.1111/nph.15680

Masutani, C., Kusumoto, R., Yamada, A., Dohmae, N., Yokoi, M., Yuasa, M., et al. (1999). The XPV (xeroderma pigmentosum variant) gene encodes human DNA polymerase eta. Nature 399, 700-704. doi: 10.1038/21447

McCulloch, S. D., and Kunkel, T. A. (2008). The fidelity of DNA synthesis by eukaryotic replicative and translesion synthesis polymerases. Cell Res. 18, 148161. doi: $10.1038 /$ cr.2008.4

McCulloch, S. D., Wood, A., Garg, P., Burgers, P. M., and Kunkel, T. A. (2007). Effects of accessory proteins on the bypass of a cis-syn thyminethymine dimer by Saccharomyces cerevisiae DNA polymerasen. Biochemistry 46, 8888-8896. doi: $10.1021 /$ bi700234t

Murakumo, Y., Roth, T., Ishii, H., Rasio, D., Numata, S., Croce, C. M., et al. (2000). A human REV7 homolog that interacts with the polymerase zeta catalytic subunit hREV3 and the spindle assembly checkpoint protein hMAD2.J Biol. Chem. 275, 4391-4397. doi: 10.1074/jbc.275.6.4391

Nakagawa, M., Takahashi, S., Tanaka, A., Narumi, I., and Sakamoto, A. N. (2011a). Role of AtPolל, AtRev1, and AtPoln in UV light-induced mutagenesis in Arabidopsis. Plant Physiol. 155, 414-420. doi: 10.1104/pp.110.166082

Nakagawa, M., Takahashi, S., Narumi, I., and Sakamoto, A. N. (2011b). Role of AtPol $\zeta$, AtRevl and AtPoln in $\gamma$ ray-induced mutagenesis. Plant Signal. Behav. 6, 728-731. doi: 10.4161/psb.6.5.15124

Nelson, J. R., Lawrence, C. W., and Hinkle, D. C. (1996). Deoxycytidyl transferase activity of yeast REV1 protein. Nature 382, 729-731. doi: 10.1038/382729a0

Nojima, K., Hochegger, H., Saberi, A., Fukushima, T., Kikuchi, K., Yoshimura, M., et al. (2005). Multiple repair pathways mediate tolerance to chemotherapeutic cross-linking agents in vertebrate cells. Cancer Res. 65, 11704-11711. doi: 10.1158/0008-5472.CAN-05-1214

Ohmori, H., Friedberg, E. C., Fuchs, R. P., Goodman, M. F., Hanaoka, F., Hinkle, D., et al. (2001). The Y-family of DNA polymerases. Mol. Cell. 8, 7-8. doi: 10.1016/ S1097-2765(01)00278-7

O-Wang, J., Kajiwara, K., Kawamura, K., Kimura, M., Miyagishima, H., Koseki, H., et al. (2002). An essential role for REV3 in mammalian cell survival: absence of REV3 induces p53-independent embryonic death. Biochem. Biophys. Res. Commun. 293, 1132-1137. doi: 10.1016/S0006-291X(02)00341-8

Pagès, V., Santa Maria, S. R., Prakash, L., and Prakash, S. (2009). Role of DNA damage-induced replication checkpoint in promoting lesion bypass by translesion synthesis in yeast. Genes Dev. 23, 1438-1449. doi: 10.1101/gad.1793409

Parent, J. S., Lepage, E., and Brisson, N. (2011). Divergent roles for the two PolIlike organelle DNA polymerases of Arabidopsis. Plant Physiol. 156, 254-262. doi: 10.1104/pp.111.173849

Pavlov, Y. I., Shcherbakova, P. V., and Rogozin, I. B. (2006). Roles of DNA polymerases in replication, repair, and recombination in eukaryotes. Int. Rev. Cytol. 255, 41-132. doi: 10.1016/S0074-7696(06)55002-8

Pedroza-Garcia, J. A., Domenichini, S., Mazubert, C., Bourge, M., White, C., Hudik, E., et al. (2016). Role of the polymerase $\epsilon$ sub-unit DPB2 in DNA replication, cell cycle regulation and DNA damage response in Arabidopsis. Nucleic Acids Res. 44 (15), 7251-7266. doi: 10.1093/nar/gkw449

Pennisi, R., Ascenzi, P., and di Masi, A. (2015). Hsp90: A New Player in DNA Repair? Biomolecules 5, 2589-2618. doi: 10.3390/biom5042589

Pozo, F. M., Oda, T., Sekimoto, T., Murakumo, Y., Masutani, C., Hanaoka, F., et al. (2011). Molecular chaperone Hsp90 regulates REV1-mediated mutagenesis. Mol. Cell. Biol. 31, 3396-3409. doi: 10.1128/MCB.05117-11
Prakash, S., and Prakash, L. (2002). Translesion DNA synthesis in eukaryotes: a oneor two-polymerase affair. Genes Dev. 16, 1872-1883. doi: 10.1101/gad.1009802

Prakash, S., Johnson, R. E., and Prakash, L. (2005). Eukaryotic translesion synthesis DNA polymerases: specificity of structure and function. Annu. Rev. Biochem. 74, 317-353. doi: 10.1146/annurev.biochem.74.082803.133250

Queitsch, C., Carlson, K. D., and Girirajan, S. (2012). Lessons from model organisms: phenotypic robustness and missing heritability in complex disease. PLoS Genet. 8, e1003041. doi: 10.1371/journal.pgen.1003041

Rattray, A. J., Shafer, B. K., McGill, C. B., and Strathern, J. N. (2002). The roles of REV3 and RAD57 in double-strand-break-repair-induced mutagenesis of Saccharomyces cerevisiae. Genetics 162, 1063-1077.

Rizzo, A. A., Vassel, F. M., Chatterjee, N., D’Souza, S., Li, Y., Hao, B., et al. (2018). Rev7 dimerization is important for assembly and function of the Rev1/Pol translesion synthesis complex. Proc. Natl. Acad. Sci. U.S.A. 115, E8191-E8200. doi: 10.1073/pnas.1801149115

Roche, H., Gietz, R. D., and Kunz, B. A. (1994). Specificity of the yeast rev3 delta antimutator and REV3 dependency of the mutator resulting from a defect (rad1 delta) in nucleotide excision repair. Genetics 137, 637-646.

Ronceret, A., Guilleminot, J., Lincker, F., Gadea-Vacas, J., Delorme, V., Bechtold, N., et al. (2005). Genetic analysis of two Arabidopsis DNA polymerase epsilon subunits during early embryogenesis. Plant J. 44 (2), 223-236. doi: 10.1111/j.1365-313X.2005.02521.x

Roy, U., Mukherjee, S., Sharma, A., Frank, E. G., and Schärer, O. D. (2016). The structure and duplex context of DNA interstrand crosslinks affects the activity of DNA polymerase $\eta$. Nucleic Acids Res. 44, 7281-7291. doi: $10.1093 /$ nar/gkw485

Sakamoto, A., Lan, V. T., Hase, Y., Shikazono, N., Matsunaga, T., and Tanaka, A. (2003). Disruption of the AtREV3 gene causes hypersensitivity to ultraviolet B light and gamma-rays in Arabidopsis: implication of the presence of a translesion synthesis mechanism in plants. Plant Cell. 15, 2042-2057. doi: 10.1105/tpc.012369

Sakamoto, A. N., Kaya, H., and Endo, M. (2018). Deletion of TLS polymerases promotes homologous recombination in Arabidopsis. Plant Signal. Behav. 13, e1483673. doi: 10.1080/15592324.2018.1483673

Santiago, M. J., Alejandre-Durán, E., and Ruiz-Rubio, M. (2006). Analysis of UV-induced mutation spectra in Escherichia coli by DNA polymerase eta from Arabidopsis thaliana. Mutat. Res. 601, 51-60. doi: 10.1016/j. mrfmmm.2006.05.036

Sarkar, S., Davies, A. A., Ulrich, H. D., and McHugh, P. J. (2006). DNA interstrand crosslink repair during G1 involves nucleotide excision repair and DNA polymerase zeta. EMBO J. 25, 1285-1294. doi: 10.1038/sj.emboj.7600993

Schimmel, J., Kool, H., van Schendel, R., and Tijsterman, M. (2017). Mutational signatures of non-homologous and polymerase theta-mediated end-joining in embryonic stem cells. EMBO J. 6, 3634-3649. doi: 10.15252/embj.2017 96948

Seki, M., and Wood, R. D. (2008). DNA polymerase $\theta$ (POLQ) can extend from mismatches and from bases opposite a (6-4) photoproduct. DNA Repair (Amst.) 7, 119-127. doi: 10.1016/j.dnarep.2007.08.005

Sekimoto, T., Oda, T., Pozo, F. M., Murakumo, Y., Masutani, C., Hanaoka, F., et al. (2010). The molecular chaperone Hsp90 regulates accumulation of DNA polymerase eta at replication stalling sites in UV-irradiated cells. Mol. Cell. 37, 79-89. doi: 10.1016/j.molcel.2009.12.015

Sharma, S., Shah, N. A., Joiner, A. M., Roberts, K. H., and Canman, C. E. (2012). DNA polymerase $\zeta$ is a major determinant of resistance to platinumbased chemotherapeutic agents. Mol. Pharmacol. 81, 778-787. doi: 10.1124/ mol.111.076828

Shima, N., Hartford, S. A., Duffy, T., Wilson, L. A., Schimenti, K. J., and Schimenti, J. C. (2003). Phenotype-based identification of mouse chromosome instability mutants. Genetics 163, 1031-1040.

Shultz, R. W., Tatineni, V. M., Hanley-Bowdoin, L., and Thompson, W. F. (2007). Genome-wide analysis of the core DNA replication machinery in the higher plants Arabidopsis and rice. Plant Physiol. 144, 1697-1714. doi: 10.1104/ pp.107.101105

Sonoda, E., Okada, T., Zhao, G. Y., Tateishi, S., Araki, K., Yamaizumi, M., et al. (2003). Multiple roles of Rev3, the catalytic subunit of pol zeta in maintaining genome stability in vertebrates. EMBO J. 22, 3188-3197. doi: 10.1093/emboj/cdg308

Stallons, L. J., and McGregor, W. G. (2010). Translesion synthesis polymerases in the prevention and promotion of carcinogenesis. J. Nucleic Acids. 2010, 643857. doi: $10.4061 / 2010 / 643857$ 
Stelter, P., and Ulrich, H. D. (2003). Control of spontaneous and damage-induced mutagenesis by SUMO and ubiquitin conjugation. Nature 425 (6954), 188-191. doi: 10.1038/nature01965

Strzalka, W., Bartnicki, F., Pels, K., Jakubowska, A., Tsurimoto, T., and Tanaka, K. (2013). RAD5a ubiquitin ligase is involved in ubiquitination of Arabidopsis thaliana proliferating cell nuclear antigen. J. Exp. Bot. 64, 859-869. doi: 10.1093/jxb/ers368

Szüts, D., Marcus, A. P., Himoto, M., Iwai, S., and Sale, J. E. (2008). REV1 restrains DNA polymerase $\zeta$ to ensure frame fidelity during translesion synthesis of UV photoproducts in vivo. Nucleic Acids Res. 36, 6767-6780. doi: 10.1093/nar/ gkn651

Takahashi, S., Sakamoto, A., Sato, S., Kato, T., Tabata, S., and Tanaka, A. (2005). Roles of Arabidopsis AtREV1 and AtREV7 in translesion synthesis. Plant Physiol. 138, 870-881. doi: 10.1104/pp.105.060236

Takahashi, S., Sakamoto, A. N., Tanaka, A., and Shimizu, K. (2007). AtREV1, a Y-family DNA polymerase in Arabidopsis, has deoxynucleotidyl transferase activity in vitro. Plant Physiol. 145, 1052-1060. doi: 10.1104/pp.107.101980

Tomida, J., Takata, K., Lange, S. S., Schibler, A. C., Yousefzadeh, M. J., Bhetawal, S., et al. (2015). REV7 is essential for DNA damage tolerance via two REV3L binding sites in mammalian DNA polymerase $\zeta$. Nucleic Acids Res. 43, 10001011. doi: 10.1093/nar/gku1385

Uchiyama, Y., Kimura, S., Yamamoto, T., Ishibashi, T., and Sakaguchi, K. (2004). Plant DNA polymerase $\lambda$, a DNA repair enzyme that functions in plant meristematic and meiotic tissues. Eur. J. Biochem. 271, 2799-2807. doi: 10.1111/j.1432-1033.2004.04214.x

Vaisman, A., Masutani, C., Hanaoka, F., and Chaney, S. G. (2000). Efficient translesion replication past oxaliplatin and cisplatin $\mathrm{GpG}$ adducts by human DNA polymerase $\eta$. Biochemistry 39, 4575-4580. doi: 10.1021/bi000130k

Vaisman, A., Frank, E. G., Iwai, S., Ohashi, E., Ohmori, H., Hanaoka, F., et al. (2003). Sequence context-dependent replication of DNA templates containing UV-induced lesions by human DNA polymerase iota. DNA Repair (Amst.) 2, 991-1006. doi: 10.1016/S1568-7864(03)00094-6

Vaisman, A., and Woodgate, R. (2017). Translesion DNA polymerases in eukaryotes: what makes them tick? Crit. Rev. Biochem. Mol. Biol. 52, 274-303. doi: 10.1080/10409238.2017.1291576

van Kregten, M., de Pater, S., Romeijn, R., van Schendel, R., Hooykaas, P. J., Tijsterman, M., et al. (2016). T-DNA integration in plants results from polymerase- $\theta$-mediated DNA repair. Nat. Plants 2, 16164. doi: 10.1038/ nplants.2016.164
Wang, S., Wen, R., Shi, X., Lambrecht, A., Wang, H., and Xiao, W. (2011). RAD5a and REV 3 function in two alternative pathways of DNA-damage tolerance in Arabidopsis. DNA Repair 10, 620-628. doi: 10.1016/j.dnarep.2011.04.009

Wittschieben, J. P., Reshmi, S. C., Gollin, S. M., and Wood, R. D. (2006). Loss of DNA polymerase $\zeta$ causes chromosomal instability in mammalian cells. Cancer Res. 66, 134-142. doi: 10.1158/0008-5472.CAN-05-2982

Wood, A., Garg, P., and Burgers, P. M. (2007). A ubiquitin-binding motif in the translesion DNA polymerase Rev1 mediates its essential functional interaction with ubiquitinated proliferating cell nuclear antigen in response to DNA damage. J. Biol. Chem. 282, 20256-20263. doi: 10.1074/jbc.M702366200

Wood, R. D., and Doublié, S. (2016). DNA polymerase $\theta$ (POLQ), double-strand break repair, and cancer. DNA Repair 44, 22-32. doi: 10.1016/j.dnarep.2016.05.003

Yoon, J. H., Prakash, L., and Prakash, S. (2009). Highly error-free role of DNA polymerase eta in the replicative bypass of UV-induced pyrimidine dimers in mouse and human cells. Proc. Natl. Acad. Sci. U.S.A. 106, 18219-18224. doi: 10.1073/pnas.0910121106

Yoon, J. H., Prakash, L., and Prakash, S. (2010). Error-free replicative bypass of (6-4) photoproducts by DNA polymerase zeta in mouse and human cells. Genes Dev. 24, 123-128. doi: 10.1101/gad.1872810

Yu, S. L., Johnson, R. E., Prakash, S., and Prakash, L. (2001). Requirement of DNA polymerase eta for error-free bypass of UV-induced CC and TC photoproducts. Mol. Cell. Biol. 21, 185-188. doi: 10.1128/MCB.21.1.185-188.2001

Zhong, X., Garg, P., Stith, C. M., Nick McElhinny, S. A., Kissling, G. E., Burgers, P. M., et al. (2006). The fidelity of DNA synthesis by yeast DNA polymerase $\zeta$ alone and with accessory proteins. Nucleic Acids Res. 34, 4731-4742. doi: 10.1093/nar/gkl465

Conflict of Interest: The author declares that the research was conducted in the absence of any commercial or financial relationships that could be construed as a potential conflict of interest.

The handling editor is currently co-organizing a Research Topic with the author, and confirms the absence of any other collaboration.

Copyright (c) 2019 Sakamoto. This is an open-access article distributed under the terms of the Creative Commons Attribution License (CC BY). The use, distribution or reproduction in other forums is permitted, provided the original author(s) and the copyright owner(s) are credited and that the original publication in this journal is cited, in accordance with accepted academic practice. No use, distribution or reproduction is permitted which does not comply with these terms. 